Journal of Mathematics and Informatics

Vol. 18, 2020, 1-14

ISSN: 2349-0632 (P), 2349-0640 (online)

Published 1 January 2020

www.researchmathsci.org

DOI: http://dx.doi.org/10.22457/jmi.v18a1160

Journal of

Mathematics and

Informatics

\title{
The Participation of Full-time Teachers in University Governance: An Empirical Study in China
}

\author{
Bing $\mathrm{Han}^{1}$, $\mathrm{Zhi} \mathrm{Liu}^{2} *$ and $\mathrm{Wei} \mathrm{Li}^{2}$ \\ ${ }^{1}$ School of Cyber Security and Information Law \\ Chongqing University of Posts and Telecommunications \\ Chongqing - 400065, Chongqing, China. \\ ${ }^{2}$ School of Economics and Management \\ Chongqing University of Posts and Telecommunications \\ Chongqing - 400065, Chongqing, China. \\ 2Address: No. 2 Chongwen Road, Nan'an District, Chongqing, 400065, China \\ "Corresponding author: E-mail: 451417524@qq.com
}

Received 30 November 2019; accepted 22 December 2019

\begin{abstract}
This study examines the participation degree and its impacting factors of fulltime teachers in Chinese university in university gonvernance, including both the academic affairs and the administrative affairs. We gathered data from 324 full-time teachers covering more than 100 universities. Three main findings were demonstrated. First, the relevance plays a decisive role in the participation of full-time teachers in governance of academic affairs and administrative affairs. Second, the diversity of participation path has a significant impact on the participation of full-time teachers in academic affairs and administrative affairs. Third, effectiveness has a substantial moderating impact on causual relationship between independent variables and the fulltime teachers' participation in academic and administrative affairs.
\end{abstract}

Keywords: full-time teacher; joint governance; University Governance, Empirical Study

AMS Mathematics Subject Classification (2010): 62B15

\section{Introduction}

Higher education institutions regard themselves as important protagonists of societal development and play a correspondingly significant role in transforming and shaping the potential sustainable society of the future (Fadeeva and Mochizuki, 2010; Leal Filho, 2012; Michelsen, 2016; Mu“ller-Christ et al., 2014). Whose potential evidences can be described as the facts that various tasks are obligatorily taken upon them including the talent cultivation in diverse fields such as the future experts, teachers, and scientists in economic, political, cultural and other fields (Bauer et al.,2018), and the undertaken enormous responsibilities and obligations enable them strive to overcome multiple challenges along the way to fulfill the expectations given by the society, due to which, the governance of universities purposed to develop themselves in effective and efficient 
Bing Han, Zhi Liu and Wei Li

way has been placed in an irreplaceable important position and itself simultaneously becomes a challenge needed to make great efforts to solve.

Many theories and methods have been put forward in literature aiming to put forward solutions with respect to the challenge mentioned above. The governance problem is proposed to solve from the perspective of the reform in university governance structures, which is thought to be helpful to find a way out in the dilemma: attempts at changing institutional arrangement and governance structures in one sector may meet with defense and conflicts from other sectors (Olsen, 2007). These reforms were considered from different perspectives including public management, policy analysis and contribution to economic growth to achieve a number of goals in common such as enhancing institutional autonomy, professionalizing the leadership of university and introducing more competition(Ferlie, Musselin, \& Andresani, 2009; de Boer et al.,2017; Gornitzka,2017). At the same time, the shared governance structure was emphasized in university governance (Scribner,2007). However, the role of teachers, which is the central element in university and may the important underlying factor in the process of university governance, has been neglected.

Some scholars emphasize the great importance of teacher, who is the central element in educational system holding various important responsibilities (Muhammad e.t.2010), thus the behaviors and attitudes of teacher should be taken much more attention to understanding. At the same time, the quality of teacher, referring to the knowledge and experiences effectively applied to teaching (Bransford, 2006) or the ability used to place impact on the students' performance in learning and researching (Tomlinson, 2000), is able to influence the efficiency of teaching, indirectly related to the performance of university governance, which has been also empirically proved to be influenced by a various of motivational constructs of teacher such as the goal orientations, enthusiasm, self-efficacy and autonomous((Butler, 2007; Frenzel, Goetz, Liidtke, Pekrun, \& Sutton, 2009; Kunter et al., 2008; Roth, Assor, Kanat-Maymon, \& Kaplan, 2007; Holzberger,2013). However, the structural segmentation inherent in high education, which enables teachers to work independently and further produce obstacles to operate with a sense of common purpose (Bonvillian and Dennis, 1995), is neglected, which makes the importance of teachers' quality in university governance diminished.

The job satisfaction, defined as a global contract or as a constellation of different dimensions to which the employee reacts effectively, is also considered as a function of motivators, whose absence contributes to increased dissatisfaction of teacher and further influence their performance in teaching in turn (Kreitner and Kinicki,2006). Therefore, inspiring the autonomy of teacher in governance affairs of universities can be seen as an alleviation between teachers and university governance, that is, encouraging teachers to participate in the governance of university affairs, detailly divided into academic affairs and administrative affairs, should be regarded as a practice which is characterized in its practical examination and perspective. However, purely encouraging teachers to actively participate in the governance of university affairs without considering the relevance of teachers with governance affairs they participated in will only increase teachers' boredom and resistance to the things that have exhausted them. At the same time, such participation of teachers in affairs of university may take up them lots of time that is 


\section{The Participation of Full-time Teachers in University Governance: An Empirical Study in China}

originally used for teaching and researching and consequently all things have been not done well.

Considering the discussion mentioned above, the improved method has been proposed in this article. Based on the long acknowledgement of the central role of fulltime teacher participating in the governance of university and the remarkable achievements that have been made in the process of being put into extensive practice in foreign countries (Chen, 2000; Robert, 2001), some work have been done to make suggestions to develop a university governance system which is better than the fact that such importance and role of full-time teachers in university governance have not aroused the necessary attention and are short of abundant researches and discussion on this topic in a wide range in domestic, which is inevitably surprising and regrettable. Specifically, some investigations and researches have been done to precisely clarify the status quo and clearly understand their ambiguous and complicated relationship between teacher participation and university governance to try to propose some advice and suggestions to perfect the interaction between teacher and university.

\section{Literature review and research hypotheses}

The relevance, referring to the status or fact of suitableness and appropriateness, is the specific concept that has received great attention in the past few years and widely used in the field of education, especially in the reform of basic education (Zhen, 2018), which is the description of the degree of suitability and commonly seen in academic research. From the general point of view, relevance can be defined as the degree of interaction between materials and multiply factors surrounded in the environment, which is usually manifested as the characteristics of appropriateness and suitability for needs. However, the relevance between the factors that contribute to the complexity and diversity of the material world can be interpreted from two aspects, one is the way of connection between components, the other is the characteristics of each factor itself, which need to be adapted to accord with the common requirements of other things beyond the intrinsic quality of things themselves. At the same time, the concept of relevance was used in the analysis of the relationship between higher education and the world of external change in the Policy Paper on Reform and Development of Higher Education in 1995, The relevance is interpreted as adherent, relevant in the English-Chinese Educational Dictionary written by Zhou (Nanzaho, 2003).

The concept of relevance has been used to analyze and research the influence mechanism of teachers' actual participation in the governance of university, aiming to use it as a tool and measure to figure out what and how the factors inherent in teachers have an impact on the action of participation in governance of university. To avoid vague in definition of relevance, the article developed the concept of relevance in the same definition as that in, that is, relevance of teacher participation in governance is regarded as the degree of matching and fit between the participating subjects and the participating matters, including the relevance of the participating subjects and the relevance of the participating matters. The relevance of the participating subjects refers to the related degree between participation and willingness of the university teachers. The relevance of 
Bing Han, Zhi Liu and Wei Li

the participating affairs refers to the related degree between affairs and teachers' responsibility or interest.

The numerous and complexed affairs of the university, representing the specific implementation of university governance, have been empirically divided into academic affairs and administrative affairs according to the summary drawn from a plenty of observation and the references in (Huafeng, 2005). Specifically, academic affairs include scientific research, teacher recruitment, and promotion and talent cultivation, administrative affairs include teacher treatment, university development, personnel selection, and assessment and student development. Based on this, the first hypothesis is showed as:

H1: The relevance has a significant decisive role in full-time teacher's participation in University Governance.

H1.1: The relevance plays a decisive role in the participation of full-time teachers in university academic affairs governance.

H1.2: The relevance plays a decisive role in the participation of full-time teachers in University administrative affairs governance.

The diversification of participation, referring to there are various of approaches for teachers to participate in the governance of university to exercise the rights and obligations as teachers and defend their own rights and interest in what they are interested in, is an important factor, which indicates the subjectivity of the teacher and the perfection of the university governance system, in which the autonomy of the teacher can be brought into practice. While the autonomy is suggested to be strongly associated with the teacher commitment due to the reduced uncertainty that accompanies the autonomy, and the sense that they have done much to contribute to the university they work in (Riehl and Sipple, 1996; Steers, 1977; Nir, 2002), therefore, the participation channels, functioned as one of the ways to achieve autonomy, differently operate according to the difference of participation in university governance. Based on the situation, the hypothesis is introduced as:

H2: The diversity of participation path has a significant decisive role in full-time teachers' participation in University Governance.

H2.1: The diversity of participation path plays a decisive role in the participation of full-time teachers in university academic affairs governance.

H2.2: The diversity of participation path plays a decisive role in the participation of full-time teachers in university administrative affairs governance.

From the general point of view, the effectiveness is a concept widely used in economics, which can be generally understood from three aspects, the first is to understand from the perspective of efficiency, which refers to obtaining the maximum output with the least input; the second is to interpret from the perspective of effect, which presents the deepen coincidence between what is actual and what is expected; the third is to be explained as benefit, indicating the ratio of input to output. Although the effectiveness of this article is not able to be discussed under the framework of economics, 


\section{The Participation of Full-time Teachers in University Governance: An Empirical Study in China}

which is incongruity with the context. Something concluded in economics can be taken to apply to the definition of the effectiveness in the article. In other words, the effectiveness in this paper mainly refers to the degree of agreement between the role expected in the process of participation and that happened in the actual situation. At the same time, the impact of government policy on the governance of universities is not taken into consideration in the article but mainly focuses on what and how the factors inherent in teachers influence the actual participation of teacher in governance of university affairs and the attempts at improving the current situation, based on this, the influence mechanism of full-time teachers in university governance is to be explained and the last hypothesis is showed as:

H3: The effectiveness has a significant moderating role on the causual relationship between relevance and diversification of participation path on full-time teacher's participation in university governance.

H3.1: The effectiveness plays a moderating role on the causual relationship between relevance and diversification of participation path on full-time teachers in university academic affairs governance.

H3.2: The effectiveness plays a moderating role on the causual relationship between relevance and diversification of participation path on full-time teachers in university administrative affairs governance.

\section{Research methodology}

\subsection{Variables}

\section{(1) Dependent variables}

The numerous and complexed affairs of the university, representing the specific implementation of university governance, have been empirically divided into academic affairs and administrative affairs according to the summary drawn from a plenty of observation and the references in (Huafeng, 2005). Specifically, academic affairs include the scientific research, teacher recruitment, and promotion and talent cultivation, administrative affairs include the teacher treatment, university development, personnel selection, and assessment and student development, based on which, the definite effect of teacher participation in university governance is concretely discussed and researched within these two frameworks, that is, the distinction of academic affairs and administrative affairs. In other words, the actual participation of teachers in different affairs is regarded as the symbol of their practical actions and presents their governance capability in both academical and administrative.

\section{(2) Explanatory variables}

The relevance, referring to the degree of matching and fit between the participating subjects and the participating matters, including the relevance of the participating subjects and the relevance of the participating matters and the diversification of participation are seen as the independent variables, which are thought to play a irreplaceable role in increasing feasibility and adhesiveness related to their own interest. The effective, regarded as a regulatory variable, presents the doubt that whether the decisions in academic and administrative are in line with their own interests and concerns 


\section{Bing Han, Zhi Liu and Wei Li}

and it is an important foundation and embodiment that can influence itself and a sign of future practical action.

\section{(3) Control variables}

Several control variables were included in the analyses. First, we control for the gender of teachers interviewed because of the stereotypical traditions and prejudices, which can impediment to their specific involvement in governance and substitute the decline of their enthusiasm and potential. To construct the variables we asked questions about the gender of respondents and the answer to the question was conducted into a single measure with the help of single-factor analysis, revealing the influence of the difference in gender on the actual participation.

Moreover, a teacher's education representing, to some extent, their capacity and potential in academic is also likely to impact on their actual participation. Therefore, the education of teachers is controlled by determining which level of education they are in, undergraduate, master or doctor. According to this setting, the impact of education on their involvement in governance can be clearly presented by controlling the education and studying the correlation between them.

Another control variable that we conclude is the professional title of the teacher. It is worth noting that the difference of professional title represents the difference of status in academic and administrative, which further influences the degree of attention and size and scope of power functions. Due to this, the professional title is taken into account to be a control variable.

Moreover, the level of the university respondents work in is regarded as one of the control variables, because the differences and levels of universities imply the richness of educational resources and the inclination of regulations, having an important impact on the intensity of talent training and actual participation indirectly.

Another, the working time of teacher is one of the control factors we consider, which is an important basis for the rise of professional titles and one of the criteria for measuring many responsibilities, directly influencing the potential of actual participation. Therefore, working time is one of the questions asked in the questionnaire and of the control variables.

Finally, we take the type of post as the control variable. Some conclusion draws from plenty of experience and observation tell us that post type directly determines the focus of their job and future development direction and approach. In other words, the consideration of post type is indispensable and necessary.

\subsection{Data collection}

Considering the fact that the complicated and uncertain relationship between full-time teachers and university management is our research objective, the full-time teachers in domestic universities are naturally chosen as the survey respondents of questionnaire distributed and recycled through the third-party professional questionnaire survey 
The Participation of Full-time Teachers in University Governance:

An Empirical Study in China

company(questionnaire star, a professional online questionnaire survey ,evaluation and voting platform aiming at providing users with powerful and user-friendly line service such as questionnaire design, data collection, self-defined report and result interpretation) and personal connections. Among the more than 1000 questionnaires having been distributed,514 usable questionnaires are collected in total from which a valid sample with a capacity of 324 is finally obtained through judging whether respondents are fulltime teachers by setting question items of "your identity category". In other words, the research on the relationship between full-time teachers and university management carries out and takes effect based on the valid sample with a capacity of 324 but not on the 514 usable questionnaires, neither on the total distribution of more than 1000 .

\subsection{Data description}

To further understand and conform the intricated and unclear relationship between teachers and university management, several factors regarded as not negligible and having a possible impact of teachers in different universities have been taken into consideration including gender, educational, professional title, category of university in service, working time and job type, directly and indirectly influencing the direction and development of management of university in some extent. Based on which, those factors abovementioned are chosen as an inseparable part of our research and their specific date distribution situation under investigation invalid sample is detailly showed. Specifically, the specific distribution of gender, education, professional title, university category universities included in 985 projects are those aiming to become first-class universities with world-class level, representing the top level in China, and included in 211 project are those referring to a number of higher education institutions and a number of key disciplines facing the 21st century, representing the high level second only to 985 project in china. In general, universities belonging to 985 projects are simultaneously part of 211 project), working time and job type situation is displayed in table 1.

Table 1: The description of statistical data

\begin{tabular}{|c|c|c|c|c|c|c|c|}
\hline \multicolumn{2}{|r|}{$0 \mathrm{ption}$} & Frequency & Proportion $(\%)$ & \multicolumn{2}{|r|}{$0 \mathrm{ption}$} & Frequency & Proportion (\%) \\
\hline \multirow{2}{*}{ Gender } & $\mathrm{M}$ an & 117 & 36.1 & \multirow{4}{*}{ Univesity } & Pro jet 985 & 85 & 26.2 \\
\hline & W om an & 207 & 63.9 & & Pro ėct 211 & 49 & 15.1 \\
\hline \multirow{5}{*}{$\begin{array}{c}\text { Professio nal } \\
\text { title }\end{array}$} & Prim ary & 74 & 22.8 & & Key un iversities & 114 & 35.2 \\
\hline & Interm ed iate & 152 & 46.9 & & 0 ther un iversities & 76 & 23.5 \\
\hline & $V$ ice-sen ior & 78 & 24.1 & \multirow{4}{*}{ Education } & Underg raduate & 67 & 20.7 \\
\hline & Senior & 12 & 3.7 & & M aster & 173 & 53.4 \\
\hline & 0 ther & 8 & 2.5 & & Doctor & 81 & 25 \\
\hline \multirow{5}{*}{$\begin{array}{l}\text { W orking } \\
\text { tim e }\end{array}$} & Less than 5 years & 118 & 36.4 & & 0 ther & 3 & 0.9 \\
\hline & $6-10$ years & 133 & 41 & \multirow{4}{*}{ Post type } & Teaching post & 250 & 77.2 \\
\hline & $11-15$ years & 53 & 16.4 & & Research post & 12 & 3.7 \\
\hline & $16-20$ years & 15 & 4.6 & & Teaching and research post & 62 & 19.1 \\
\hline & M ore than 21 years & 5 & 1.5 & & & & \\
\hline
\end{tabular}

\section{Regression results}

\subsection{Full-time teacher's participation in governance of academic affairs}

Considering the deficiency of interpretation between the control variables and dependent variables, the regulatory effect has been taken into consideration to enrich and perfect the potential possibilities existed among variables. To achieve the aims, the relevance and diversity of participation have been respectively linked together to the effectiveness to 
Bing Han, Zhi Liu and Wei Li

become a new individual variable, respectively naming effectiveness-relevance and effectiveness-diversification, to explain the regulation of effectiveness in academic affairs.

Regression results are shown in Table 2 . The results using linear regression indicate the fact that firstly the value of $\mathrm{R}$ square, meaning the goodness of fit, indirect effect $(0.278)$ is smaller than that in regulation $(0.321)$, that is, the independent variable can explain the variance of the dependent variable by $27.8 \%$ indirect effect but by $32.1 \%$ in regulation, which makes clear that the validity in light of regulation of effective and the join of effective makes our account for the influence mechanism between teachers and university governance more closely to the actual situation.

Another, the fact that the significance both invariance analysis of direct effect and regulatory effect in academic affairs is 0.000 , notably less than 0.05 , indicates the statistical significance, which gives eloquent proof to the availability of regression equation. Moreover, considering the fact that the relevance and diversification of participation are the independent variables and effective is the explanatory variable, therefore, the study of the two has to be carried out from different dimensions. In terms of the relevance and diversification of participation, whose significance studies should be operated within the framework of direct effect. And the result concluded from the analysis of the coefficients indicates the significance of both relevance and diversification of participation are significantly less than 0.05 (the former is 0.000 and the latter is 0.005), which tells us the fact that the relevance and diversification of participation play a decisive role in the participation of full-time teachers in the academic affairs of universities, That is to say, hypothesis 1.1 and hypothesis 2.1 are verified.

Finally, in terms of the effectiveness, whose significance study should be operated within the framework of regulatory/moderation effect. And the result concluded from the coefficients analysis indicates the significance of both effective-relevance and effectivediversification of participation are significantly less than 0.05 (the former is 0.044 and the latter is 0.006), which all have statistically significant characteristics, explaining the correctness of hypothesis 3.1. That is to say, effectiveness has a decisive moderating role in the participation of full-time teachers in the governance of academic affairs in universities. At the same time, the positive value of beta of effectiveness -relevance in unstandardized coefficients further tells us the fact that the moderation effect of effectiveness is positive and significant. However, the negative value of beta of effectiveness - diversity of participation path in unstandardized coefficients illustrates that the moderation effect of effectiveness in this casual relationship is negative and significant.

\subsection{Full-time teacher's participation in governance of administrative affairs}

Based on the same consideration as that in academic affairs, the same variable setting and arrangement are also applied in the study of the influence mechanism of the actual participation degree of administrative affairs to further figure out what and how these variables potentially exert influence on the actual participation of teacher in the governance of administrative affairs. Simultaneously, the combination of effectiveness- 
The Participation of Full-time Teachers in University Governance:

An Empirical Study in China

relevance and effectiveness-diversification is automatically applied to the explanation of the regulation of effectiveness in administrative affairs.

Regression results are shown in Table 3. The results of the linear regression in administrative affairs are presented in table 4, indicating the fact that firstly the $\mathrm{R}$ square, meaning the goodness of fit, differently values within the framework of direct effect and of regulation, whose value is 0.277 in the former and 0.328 in the latter. In other words, the fact based on mentioned above that the former value of $\mathrm{R}$ square is smaller than that in later tell us that the explanation of direct effect is not as great as that of regulatory effect, indirectly demonstrating the validity in light of regulation of effective and the join of effective makes our account for the influence mechanism between teachers and governance in administrative affairs more closely to the actual situation. The result concluded from the single factor analysis explains the statistically significance of the variable, whose evidence is the fact that the significance both invariance analysis of direct effect and regulatory effect in administrative affairs is 0.000 , notably less than 0.05 , further giving eloquent proof of the significance of regression equation.

Table 2: Regression result table of academic affairs

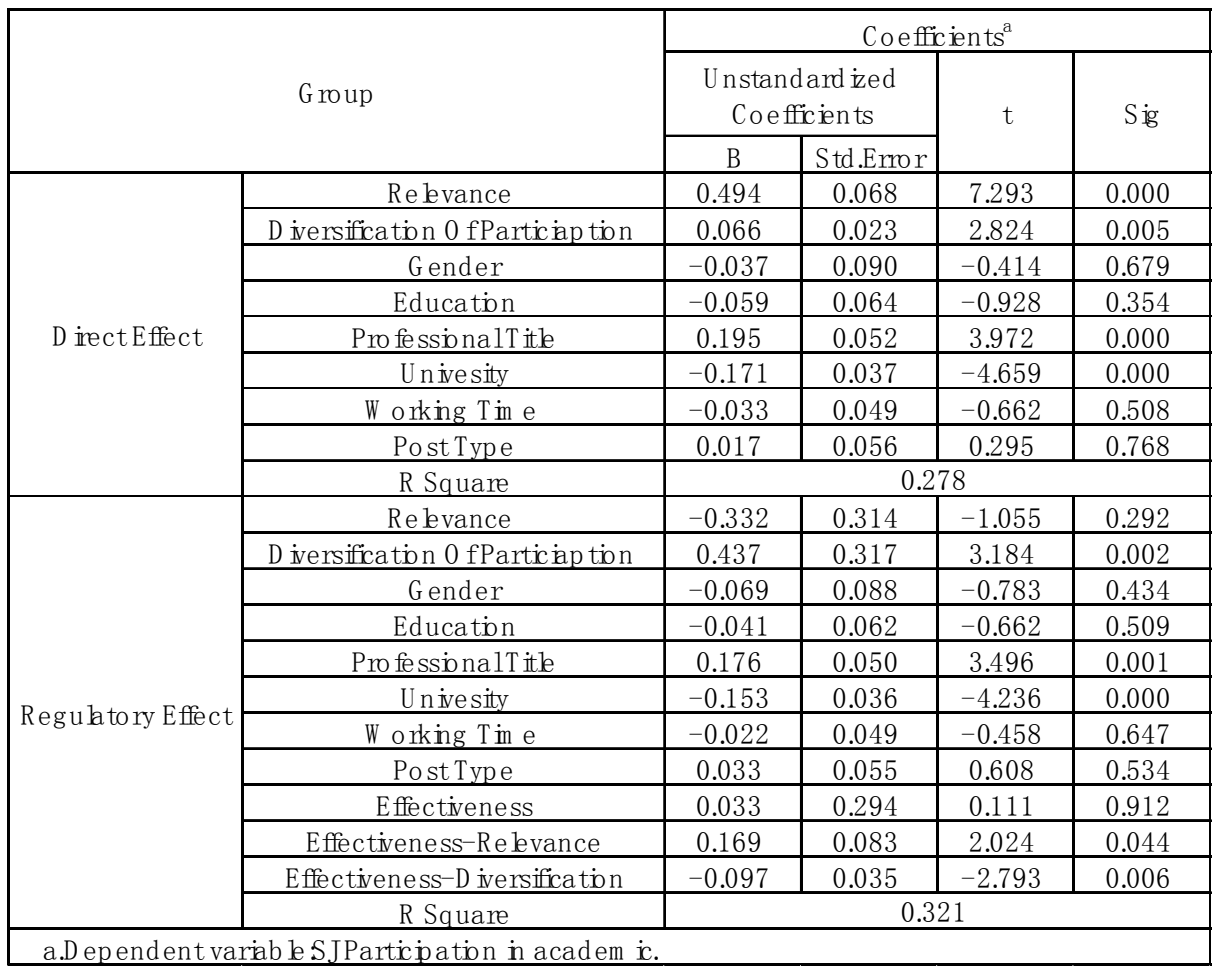

Moreover, the relevance, diversification of participation and effectiveness are different types of variables, that is, the former two are independent variables and the latter one is explanatory variable. Based on which, these three, divided into two 
Bing Han, Zhi Liu and Wei Li

categories, are conducted within the different frameworks. In terms of the relevance and diversification of participation, whose results concluded from the coefficients analysis which are operated within the framework of direct effect indicate the fact that the significance between relevance, diversification of participation and the actual participation of full-time teacher in administrative affairs are respectively 0.000 and 0.039 significantly less than 0.05 , which tells us the fact that the relevance and diversification of participation play a decisive role in the participation of full-time teachers in the administrative affairs of universities, that is to say, hypothesis 1.2 and hypothesis 2.2 are verified.

Finally, the result of the effectiveness in coefficients analysis, which is conducted within the framework of regulatory effect, indicates the significance of effectiverelevance and effective-diversification of participation are respectively 0.05 and 0.006 , both significantly less than 0.05 , meaning that the moderating role of effectiveness in the causual relationships between relevance and diversity of participation path and participation of full-time teacher in administrative affairs are all significant. Therefore, the hypothesis 3.2 is supported.

Table 3: Regression result table of administrative affairs

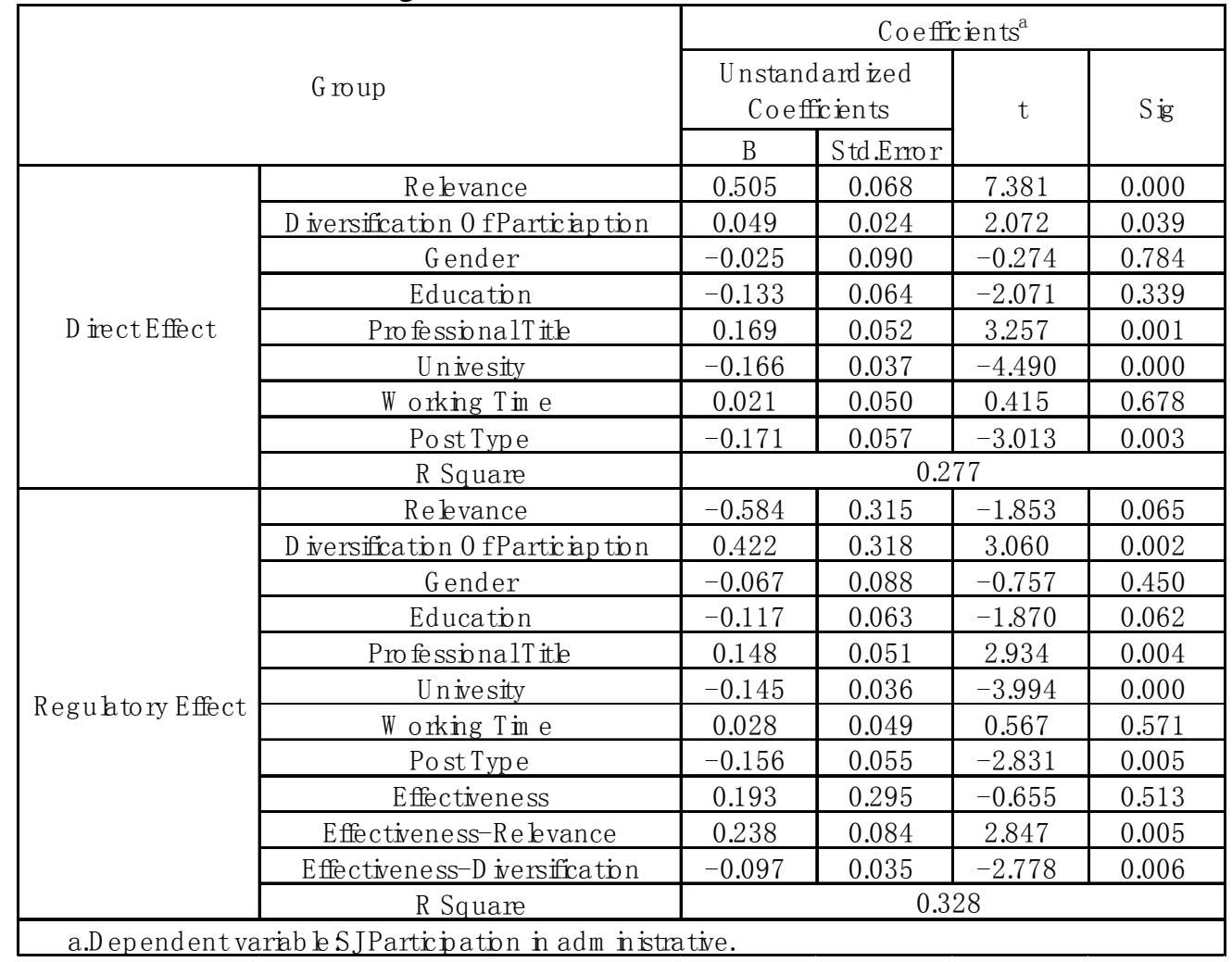

\section{Conclusions and discussion}

The central aim in this article has been to develop more systematic research of the actual participation of full-time teachers in academical affairs and administrative affairs 
The Participation of Full-time Teachers in University Governance: An Empirical Study in China

respectively and give a more comprehensive account of the influence mechanism of fulltime teachers in university governance. In more detail, we have addressed the question of what, how and under which condition the full-time teachers have the highest level of practical actions to participate in the governance of universities, specifically, the management of scientific research, teacher recruitment and promotion, talent cultivation, teacher treatment, university development, personnel selection, and assessment and students development. Research on the performance of teachers' actual participation in the university governance has, to some extent, acknowledged that teachers with different gender, education, professional title, universities in service, working time and post type have practical action to a varying degree to be dedicated to the construction of some aspects of the university. Simultaneously, some facts have been found that several vital factors such as professional title, university in service and working time significantly affect the actual participation of teacher both in academic affairs and administrative affairs, and the effectiveness, regarded as moderator variable, relevance and diversity of approaches to participation, regarded as independent variables of explanatory variable, have been take into consideration to illustrate the complicated relationship between control variables such as gender and dependent variables such as the actual participation in academic affairs.

Overall speaking, the result proceeded using single-factor analysis can basically demonstrate several clear facts. Firstly, whether man or female, undergraduate or postgraduate education had no notable impact on teachers' participation in academic and administrative affairs, in other words, gender and education are not the factors having the potential to influence the trend and level of teachers' actual participation in academic and administrative affairs. Second, the type of post is the special factor being able to produce an effect on the degree of actual participation of teacher, however, the influence of this effect is partial and restricted, that is, the type of position only affects the scientific research in academic affairs and treatment of teachers in administrative affairs, and the results indicate that the teachers of the teaching and researching posts have the highest actual participation in the management of the university, while the teachers of teaching post have the lowest. Finally, several factors, specifically the professional title, university in service and working time, have been proved to be momentous elements generally affecting all aspects of academic affairs and administrative affairs and have the identical characteristics in all aspects: The actual participation in the management of colleges and universities will significantly improve with the promotion of professional titles and reach the highest level in senior professional titles; teachers in universities included in 985 projects have the highest participation compared with those in other lower universities, which show low participation almost indiscriminately; An important watershed in working hours is five years, teachers who work less than this time have a significantly low level of participation and who are more than 10 years of working age will also gradually decline in degree of participation with time increases.

In addition, the effectiveness has been additionally added to take into consideration to determine the interaction between control variables and dependent variables, and the 


\section{Bing Han, Zhi Liu and Wei Li}

analysis result with linear regression indicates that the moderating effect of effectiveness on the connection between variables can be described as remarkably apparent, in other words, the existence of effectiveness makes the control variables and dependent variables inextricably bound together and plays a significant regulatory role. However, the negative correlation between the diversity of participatory approaches and effectiveness does not explain the failure of the regulatory role in which effectiveness is exerted. This failure is due to the fact teachers play a role in a form that is not valued in the given ways to participate. In fact, passivity is the only role they played in the process of participation.

Finally, the six hypotheses set up in the previous paper are verified in different dimensions and proved their correctness, that is,

(1) the relevance plays a decisive role in the participation of full-time teachers in governance of academic affairs and administrative affairs;

(2) the diversity of participation has a significant impact on the participation of fulltime teachers in academic affairs and administrative affairs.

(3)Effectiveness has a substantial impact on full-time teachers' participation in academic and administrative affairs.

Acknowledgements. This research is supported by a Twelfth Five-Year Plan for Educational Science Project in China (Grant No. BIA140096). The authors are also thankful to the reviewers for the comments for improvement of the paper.

\section{REFERENCES}

1. Z.Fadeeva and Y.Mochizuki, Higher education for today and tomorrow: university appraisal for diversity, innovation, and change towards sustainable development, Sustainability Science, 5(2) (2010) 249-256.

2. W.Leal Filho (ed.). Sustainable Development at Universities, Frankfurt: Peter Lang (2012).

3. G.Michelsen, Policy, politics and polity in higher education for sustainable development, in M. Barth, G. Michelsen, I. Thomas and M. Rieckmann (eds.) Routledge Handbook of Higher Education for Sustainable Development, London: Routledge, (2016)40-55.

4. G.Mu"ller-Christ, S.Sterling, R.van Dam-Mieras, M.Adomßent, D.Fischer and M.Rieckmann, The role of campus, curriculum, and community in higher education for sustainable development - a conference report, Journal of Cleaner Production, 62 (2014) 134-137.

5. M.Bauer, I.Bormann, B.Kummer, S.Niedlich and M.Rieckmann, Sustainability governance at universities: using a governance equalizer as a research heuristic, Higher Education Policy, 31(4) (2018) 491-511.

6. J.P.Olsen, The institutional dynamics of the European university. In P. Maassen \& J. P. Olsen (Eds.), University dynamics and European Integration, Dordrecht, the Netherlands: Springer, (2007) 25-55.

7. E.Ferlie, C.Musselin and G.Andresani, The governance of higher education systems: A public management perspective. In C. Paradeise, E. Reale, I. Bleiklie, \& E. Ferlie (Eds.), University governance. Western European comparative perspectives (pp. 119). Dordrecht, the Netherlands: Springer (2009). 
The Participation of Full-time Teachers in University Governance:

An Empirical Study in China

8. H.de Boer, J.File, J.Huisman, M.Seeber, M.Vukasovic and D.F.Westerheijden, Policy analysis of structural reforms in higher education. Processes and outcomes, New York, NY: Palgrave Macmillan (2017).

9. P.Gornitzka, Maassen, and H.De Boer, Change in university governance structures in continental Europe, Higher Education Quarterly, 71(3) (2017) 274-289.

10. J.P.Scribner, R.K.Sawyer, S.T.Watson and V.L.Myers, Teacher teams and distributed leadership: a study of group discourse and collaboration, Educational Administration Quarterly, 43(1) (2007) 67-100.

11. M.E.Malik, S.Nawab, B.Naeem, R.Q.Danish, Job satisfaction and organizational commitment of university teachers in the public sector of Pakistan, International Journal of Business and Management, 5(6) (2010) 34-44.

12. J.Bransford, L.Darling-Hammond and P.Le Page, Introduction, in DarlingHammond, L. and Bransford, J. (Eds), Preparing Teachers for a Changing World: What Teachers Should Learn and be Able to Do, Jossey-Bass, San Francisco, CA, (2005) 1-39.

13. C.A.Tomlinson, Reconcilable Differences: standards-based teaching differentiation, Educational Leadership, 58 (1) (2000) 6-11.

14. R.Butler, Teachers' achievement goal orientations and associations with teachers' help-seeking: Examination of a novel approach to teacher motivation, Journal of Educational Psychology, 99 (2007) 241-252.

15. A.C.Frenzel, T.Goetz, O.Lüdtke, R.Pekrun and R.E.Sutton, Emotional transmission in the classroom: Exploring the relationship between teacher and student enjoyment, Journal of Educational Psychology, 101 (2009) 705-716.

16. Kunter, M., Tsai, Y.-M., Klusmann, U., Bmnner, M., Krauss, S., \& Baumert, J. Students' and mathematics teachers' perceptions of teacher enthusiasm and instruction. Leaming and Instruction, 18 (2008)468-482.

17. G.Roth, A.Assor, Y.Kanat-Maymon and H.Kaplan, Autonomous motivation for teaching: How self-determined teaching may lead to self-determined leaming, Journal of Educational Psychology, 99 (2007) 761-774.

18. D.Holzberger, A.Philipp and M.Kunter, How teachers' self-efficacy is related to instructional quality: a longitudinal analysis, Journal of Educational Psychology, 105(3) (2013) 774-786.

19. G.Bonvillian and T.L.Dennis, Total quality management in higher education: opportunities and obstacles, in Sims, S.J., and Sims, R.R. (Eds), Total Quality Management in Higher Education: Is it Working? Why or Why Not? Praeger, Westport, CT, (1995) 37-50.

20. R.Kreitner and A.Kinicki, Organizational Behavior. New York: McGraw Hill (2006).

21. R.P.Chen, History of American educational management thoughts. Hainan Publishing House, (2000) 136-137.

22. R.G.Owens, Educational organizational behavior, East China Normal University Press, (2001) 350-354.

23. Z.Nanzhao et al., English-Chinese Educational Dictionary, Beijing: Science Education Press, (2003) 509.

24. W.Huafeng, Administration and academical: analysis of the three dimensions on the governance of universities, 2016. 
Bing Han, Zhi Liu and Wei Li

25. C.Riehl and J.W.Sipple, Making the most of time and talent: secondary school organizational climates, teaching task environments, and teacher commitment, American Educational Research Journal, 33(4) (1996) 873-901

26. R.M.Steers, Antecedents and outcomes of organizational commitment, Administration Science Quarterly, 22(1) (1977) 46-56.

27. A.E.Nir, School-based management and its effect on teacher commitment, International Journal of Leadership in Education, 5(4) (2002) 323-341. 